\title{
La sinagoga del Tránsito en la Edad Moderna: abandono, mantenimiento, restauración
}

Inocencio Cadiñanos Bardecí

\begin{abstract}
Poco después de 1492, la sinagoga (a posteriori denominada) del «Tránsito» (de Nuestra Señora) fue convertida en iglesia del priorato de San Benito de la orden de Calatrava, pasando a ser archivo de las órdenes de Calatrava y Alcántara. Pese a su conocido valor artístico, la historia del monumento durante la Edad Moderna es aún desconocida en gran medida. Basándose en documentación conservada en el archivo de la Real Academia de Bellas Artes de San Fernando y en el fondo de Órdenes Militares del Archivo Histórico Nacional, el autor repasa en este artículo el proceso de mantenimiento y restauración del monumento, cuyo emplazamiento y uso como iglesia y archivo evitaron su abandono y ruina.
\end{abstract}

Palabras Clave: sinagogas; Toledo; patrimonio; restauración; bellas artes; Edad Moderna (siglos XVII-XVIII).

The Transito Synagogue in the Early Modern Period: Neglect, Maintenance, Restoration.Soon after 1492, the (so-called) Transito synagogue became the San Benito priory chapel of the Calatrava Order and then archive of the Orders of Calatrava and Alcantara. Despite its artistic value, the history and fate of this monument, especially during the early Modern Period is far from being known. Based on documentary evidence from the San Fernando Royal Academy of Fine Arts and the Military Orders Section of the National Historical Archives, the author delineates the process of maintenance and restoration of the monument. $\left.18^{\text {th }} \mathrm{c}.\right)$.

KeYwords: Synagogues; Toledo; Heritage; Restoration; Fine Arts; Early Modern Period (17 ${ }^{\text {th }}$

En 1964 se creaba en Toledo el Museo Sefardí dentro del recinto de la sinagoga del Tránsito. Con el contenido de historia y cultura de los judíos en España y en la diáspora sefardí, incluyendo también la Antigüedad bíblica, la sinagoga había sido reabierta en 1971 siendo su primer director el hebraísta Francisco Cantera Burgos '. El edificio había sido reformado anteriormente en diferentes ocasiones, con elementos añadidos como la ventana geminada que hoy luce

\footnotetext{
${ }^{1}$ Para una visión sucinta de la ocupación del edificio a lo largo de los siglos, véase S. Palomero PlazA, «Apuntes historiográficos sobre la sinagoga del Tránsito», en El legado material hispanojudio, coord. A. M. López Álvarez, R. IzQuierdo Benito (Cuenca 1998), págs. 143-180.
} 
sobre la puerta de ingreso, que aparece en la segunda mitad de siglo y que investigadores como Torres Balbás tacha de «inventada», diferente de los vanos del interior ${ }^{2}$.

Los inicios del uso actual del edifico están relacionados con el marqués de la Vega-Inclán, comisario regio de turismo desde 1911, que se preocupó por su conservación y recuperación. Los arquitectos Enrique M. Repullés y Eladio Laredo habían presentado proyectos para su reparo e instalación de una biblioteca anexa, como centro de estudios hebraicos. En 1913 Laredo había desmontado el andamiaje levantado anteriormente por Arturo Mélida y comenzaba a trabajar eliminando añadidos, dejando al descubierto atauriques y lacerías. De esta manera, la antigua sinagoga de Šemuel ha-Leví comenzaba a recuperar un aspecto más próximo a su estado original. Viejas fotografías nos muestran la situación del edificio en la década de 1930: una fachada con espadaña, puerta de ingreso con tejadillo y encima el mencionado balcón, desvencijado, desconchado y con aspecto de desagradable abandono.

El arquitecto director Arturo Mélida había solicitado permiso para poder levantar las inscripciones bajas con el fin de reforzar la fábrica en aquel punto. Dudaba sobre si debía restaurarse como antigua sinagoga o como iglesia cristiana que también había sido. La Real Academia de Bellas Artes ordenaba hacerse como sinagoga, manteniendo el arcosolio y puerta de la sacristía platerescos así como las laudas sepulcrales del suelo que lucían escudos e inscripciones de caballeros de Calatrava. Poco después, la misma academia se quejaba ante la Dirección General de Instrucción Pública del mal estado de la techumbre del edificio con multitud de goteras ${ }^{3}$.

La declaración del edificio como monumento nacional en 1877 había salvado a este de la enajenación, ruina y hasta algún intento de demolición. Serían la celosa intervención de la Comisión Provincial de Monumentos de Toledo y la vigilancia de la Comisión Central de la Real Academia de San Fernando, las que exigieron su cuidadosa restauración, sin permitir alteración alguna de lo considerado como elementos originales. Precisamente la documentación de esta academia y la de la Orden de Calatrava, custodiada originalmente en el Tránsito,

${ }^{2}$ B. Pavon Maldonado, «Un problema arqueológico en la sinagoga de El Tránsito» Sefarad 36 (1976), págs. 141-144.

${ }^{3}$ J. de D. Rada Delgado, «La sinagoga mayor de Toledo», Boletín de la Real Academia de la Historia 37 (1900), págs. 485-487; E. M. REPULLÉS VARGAS, «Informe acerca del proyecto de obra para reforma en la sinagoga del Tránsito de Toledo (hoy Museo del Greco)», Boletín de la Real Academia de Bellas Artes de San Fernando (1913), pags. 89-90. 
han servido de base para el presente trabajo ${ }^{4}$. Los reparos anteriores a mediados del siglo XIX, -adaptaciones funcionales y aislamiento de humedades- apenas eran conocidos hasta aquí y se hicieron en función del interés de sus usufructuarios. Solo en alguna ocasión se aconseja respetar lo existente, dejando la nave central y la restauración sin alterar las inscripciones. Aún así, la fachada principal sería bastante alterada, y otro tanto habría que decir del ábside, acondicionado para la nueva función como capilla cristiana.

\section{Después de 1492: priorato de San Benito de la orden de Calatrava}

Dos años después de la expulsión de los judíos, el edificio pasa a la orden de Calatrava, convertida en priorato de San Benito. A través de los siglos tendrá la consideración de iglesia, ermita y hasta será calificada de parroquia, lo que nunca fue. Cuando a principios del siglo XVII se funda en Toledo un convento de religiosas de San Benito, se produce cierta confusión de nombres. Por esto, el priorato comienza a ser conocido popularmente como de «Nuestra Señora del Tránsito» por el cuadro de Correa de Vivar que lucía en uno de sus altares ${ }^{5}$, nueva denominación que irá imponiéndose desde comienzos del siglo XVIII hasta desterrar por completo a la anterior.

La orden de Calatrava tuvo en la ciudad un priorato (San Benito) y una encomienda (Casas de Toledo), que no deben identificarse o confundirse, pues fueron completamente distintos. El priorato había sido creado en el siglo XIII. Tras la donación de la sinagoga, la pequeña comunidad de frailes desaparece quedando, únicamente, un prior y servidores que se instalan en viviendas anejas a la sinagoga. El jardín posterior cedido en el siglo XVIII, sería donación de fray Antonio de Céspedes y Calderón.

Frente a la encomienda que dispuso de notables ingresos, nuestro priorato fue uno de los más pobres de la orden. Priorato -se le decía- «alejado», dependiente del partido de Almonacid de Zorita. Sus rentas provenían de tierras, huertas, casas, una forja y un molino en El Tiemblo que rendían anualmente 962 reales y 6 cahíces de pan mediado. Varias de sus tierras en Aranjuez serían agregadas al Real Sitio por el rey Carlos I. Aún a principios del siglo XIX el priorato

${ }^{4}$ Siguen siendo valiosos los análisis estilísticos descriptivos de E. LAMBERT, «Les synagogues de Tolède», RÉJ 84 (1927), págs. 15-33; y F. CANTERA Burgos, Sinagogas de Toledo, Segovia y Córdoba (Madrid 1973), págs. 49-138.

${ }^{5}$ Véase, I. Cadiñanos Bardecí, «Precisiones acerca del Tránsito de la Virgen de Juan Correa de Vivar», Boletín del Museo del Prado XXIV, n. ${ }^{\circ} 42$ (2006), págs. 6-13. 
percibía 8.831 reales que, tras la rebaja de las cargas, se quedaban en 5.645. Tan menguados ingresos obligarían a que los costosos reparos del conjunto de edificios fueran pagados por la mesa maestral debido, en buena parte, a que en este edificio se situará el archivo de toda la orden de Calatrava.

$\mathrm{El}$ aspecto interno de la antigua sinagoga cambia por completo con la adaptación a la nueva función. La sacristía posee un ingreso de estilo plateresco datable hacia 1513, obra de Cristóbal de Palacios como lo recuerda una de las inscripciones. Los escudos que la adornan así como los de la clave de la cubierta del interior, nos están hablando de los apellidos calatravos que la encargaron y pagaron: Silvas, Ulloas, Manriques, entre otros.

El retablo mayor ha desaparecido. Estuvo rematado con una gran corona. Por sus reducidas dimensiones se adaptó perfectamente al muro oriental, aprovechando la antigua ornamentación hebrea como complemente decorativo, y el sagrario sería sustituido en el siglo XVIII por otro barroco.

Hubo otras dos capillas laterales con sendos altares. La del lado del evangelio estuvo dedicada a San Benito y al Santo Cristo. Constó de un retablo con la figura del primero y otros tres santos, un Cristo, una imagen de la Soledad, Santa Elena y la Magdalena. A veces se le denomina retablo de San Miguel con cinco santos en tabla en su contorno. En el lado opuesto destaca muy bien conservado un arcosolio plateresco encargado en 1547 por don Iñigo de Ayala y Rojas, cuyo escudo le corona. Su retablo fue muy popular y admirado entre los toledanos. Se trata del excelente cuadro del Tránsito de Correa de Vivar, que daría nuevo nombre a la sinagoga (hoy, en el Museo del Prado).

A fines del siglo XVI se proponía convertir este conjunto de edificios en casa de acogida de sacerdotes pobres y ancianos, lo que no tendría efecto. Las normas de la Orden dejaron bien claro que el prior debía mantener todo en perfecto estado pues, en caso contrario, sería reparado a costa de sus ingresos. Durante el siglo XVI el arreglo del templo y casas adyacentes corre al cuidado y por cuenta del prior, y por tratarse de un asunto privado no se conserva documentación alguna. Pero desde la instalación del archivo a espaldas de la antigua sinagoga, los reparos correrán a cargo de la mesa maestral, de lo que ha quedado constancia.

Situación, inventarios y reparos en el siglo XVII: el archivo

En 1628 se menciona por primera vez el depósito de los archivos de las órdenes de Calatrava y Alcántara, aunque se trata únicamente de la sección judicial 
y de algunos papeles del Consejo de Ordenes, pues el resto de la documentación continúa en sus respectivos archivos de los conventos de Calatrava y San Benito de Alcántara. Esa documentación llega al Tránsito a comienzos de siglo, donde permanece hasta su envío al Archivo Histórico Nacional en 1899.

A mediados del siglo XVII se denuncia el estado ruinoso general tanto del archivo como de la iglesia, y comienza la disputa acerca de en quién debía recaer el coste, alegando el prior que era asunto de la orden de Calatrava pues allí se encontraba su archivo y no debía pagar la de Alcántara, ya que esta solamente lo tenía alquilado. En 1652 el rey ordena que, en adelante, todas las obras corriesen por cuenta de la mesa maestral ${ }^{6}$.

Desde 1655 se conservan repetidos inventarios realizados cada vez que toma posesión un nuevo prior, y se hacen constar con detalle las obras de restauración efectuadas. En dicho año se cita el retablo mayor, lámparas, cruces y cálices de plata sobredorados, un sagrario antiguo con reliquias, así como otros objetos cultuales. Los retablos colaterales estaban dedicados al Santo Cristo y a Nuestra Señora de la Asunción (Tránsito) aislado por una verja por ser de patronato particular.

En 1679 se nos describe la situación de la iglesia con algún detalle: unas puertas grandes de entrada «con cerraduras de lobos», y sobre ellas una ventana con una reja de hierro. En el zaguán, un sótano y una puerta de entrada al archivo. El retablo mayor «con muchas insignias», así como un relicario (sagrario) pequeño de plata. Las capillas laterales presentaban modificaciones, y la tribuna con rejas de palo y «con una columna de piedra que la sustenta en medio», en referencia a lo que se considera antigua galería de mujeres, conservada casi intacta. Los reparos fueron señalados por el maestro Juan Rodríguez, y se centraban en el acondicionamiento del altar mayor, bóvedas, sacristía y parte de las dependencias, por un coste de 1.497 reales. Al año siguiente se repetían reparos con un presupuesto más reducido.

Al ser insuficiente el presupuesto disponible, años más tarde, al tomar posesión el nuevo prior, este intenta endosar el costo de las obras necesarias a su antecesor. Tanto la iglesia como las viviendas se encontraban en mal estado, según informó el albañil Diego de Medina. Era preciso asegurar las puertas de entrada, solar la iglesia y portal con ladrillo, consolidar el retablo y mesa de altar, los muros estaban desconchados y los tejados en mal estado. Las obras costarían 2.803 reales y eran urgentes por el riesgo de ruina total.

${ }^{6}$ Las referencias documentales para este capítulo están sido tomadas de Archivo Histórico Nacional, Madrid (= AHN), Órdenes Militares (= OM), legs. 3670, 5243, 5244, 6034 y 6035. 
Poco o nada pudo hacerse entonces, aunque la documentación abunda en la descripción de aspectos nuevos. La puerta de entrada a la iglesia poseía, ahora, unas rejas recientemente colocadas. Bajo el coro y tras una puerta había «un pozo que solía ser aljibe». En la azotea colgaban las campanas, y por tanto no existía aún la espadaña actual.

Hasta finalizar el siglo no se da comienzo a reparos sustanciales. Quedó el altar asentado sobre ladrillos. Después, con la llegada de nuevas remesas de documentación, se siguió ampliando el archivo bajo la tribuna de las mujeres. El emplazamiento húmedo del templo exigió el acondicionamiento de una puertecilla del testero que salía a un jardincillo y un grueso trabajo que ha dado lugar a equivocadas interpretaciones. Se centró en la esquina del sudoeste de la fachada principal de la sinagoga que hubo que rehacerse en ladrillo y afianzarla con un fuerte pilar, que nada tuvo que ver con una pretendida torre medieval, como había señalado Pavón Maldonado ${ }^{7}$. El cantero Pedro González evaluó el reparo en 9.556 reales. Allí pudo estar el pozo-aljibe que había causado la ruina.

\section{Mantenimiento en el siglo XVIII}

Desde los primeros momentos de siglo disponemos de algunas noticias del priorato, que disponía de rentas mayores, y esta centuria será de notable intervención en el acondicionamiento del conjunto de edificios, especialmente la iglesia, ahora ya habitualmente denominada de «Nuestra Señora del Tránsito».

En 1718 es ampliado el archivo (de las órdenes de Calatrava y Alcántara») como consecuencia de la orden real de que se remitieran a él todos los papeles fechados hasta la muerte de Carlos II. Se trata de una obra de envergadura, consistente en el edificio adosado al norte de la sinagoga. Proyectado por Ignacio Arias y Juan Alvarez Puerta, y evaluado inicialmente en 8.550 reales, sería adjudicado por 6.500 y llevado a cabo por el maestro Feliciano de Talavera.

En 1733 se produce una importante intervención en la iglesia. Francisco Moreno idea un nuevo tabernáculo «arreglado al que nuevamente se ha puesto en la parroquial de San Andrés desta ciudad», tallado por el platero Vicente Juárez por 1.470 reales, espectacular y al más puro gusto barroco (fig. 1).

\footnotetext{
${ }^{7}$ Pavon Maldonado, «Un problema arqueológico», pág. 143.
} 


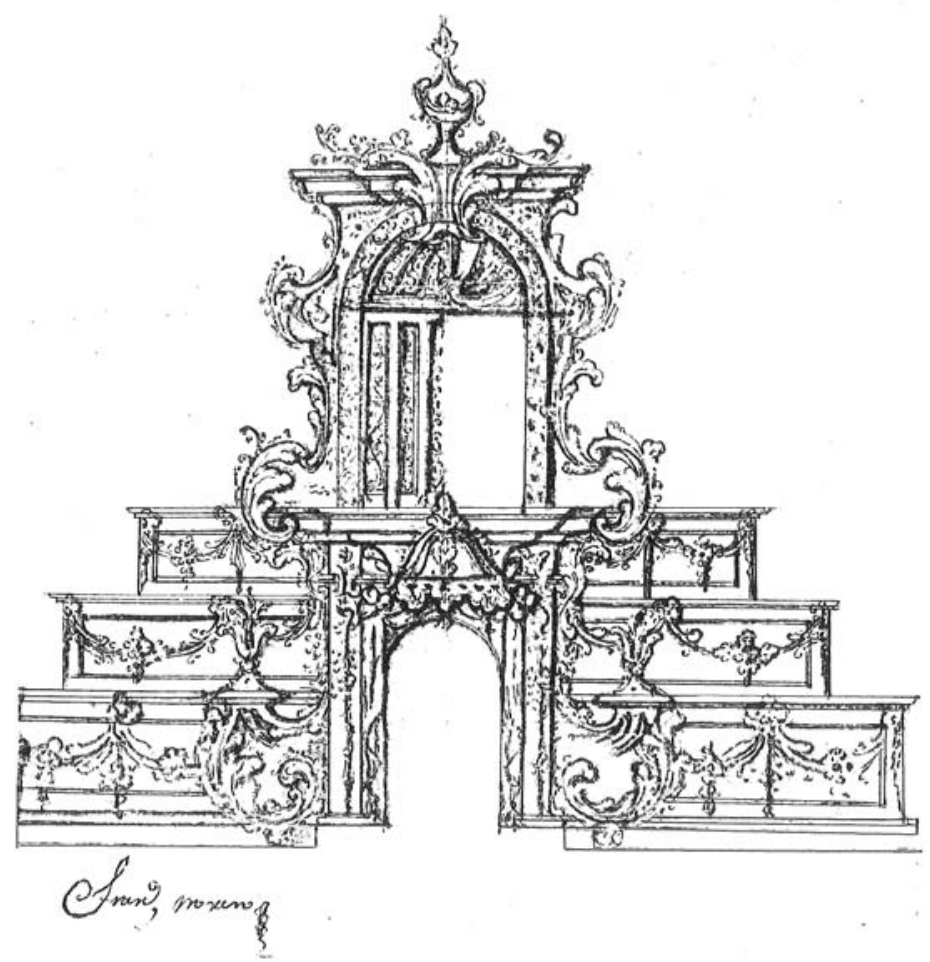

Fig. 1. Tabernáculo del retablo mayor. Diseñado por Francisco Moreno y tallado por Vicente Juárez (AHN, OM, leg. 5244).

Las obras menores fueron numerosas, y entre ellas habría que destacar la colocación de nuevas vidrieras en las ventanas de la tribuna, y el solado del templo con ladrillo raspado. Para esto hubo que levantar 21 sepulturas bajo las que no se encontró ningún vestigio, lo que hace pensar que se trataba de meros cenotafios, o quizás se habría producido un traslado anterior de los restos humanos. A lo largo de estos años se plantea de nuevo la disputa acerca del pago de las obras, que recaería sobre la mesa maestral, según reglamento real de 1719 y orden de Fernando VI ${ }^{8}$.

A pesar de los trabajos de aislamiento del testero del templo, a mediados de siglo se advierte la gran humedad que hacía peligrar los estucos con inscripciones hebreas. Fueron renovadas entonces las vidrieras de la iglesia y sacristía, que se corresponden en buena parte con las actuales. Se tendió un porche sobre el ingreso

${ }^{8}$ Las referencias documentales para este capítulo están tomadas de AHN, OM, legs. 3670, $5243,5244,6034$ y 6035 . 
principal y se adorna su parte superior con escudos pintados de Calatrava, que han permanecido hasta tiempos bien cercanos, como recuerda Palomares ${ }^{9}$.

Esta obra sería ampliada poco después con otras más complejas según proyecto de los maestros Pablo Sánchez y Manuel Gómez. Imaginaron un pórtico de $12 \mathrm{~m}$ de largo por 5,50 de ancho que recorría la entrada. Encima un balcón de 7 pies de longitud por un pie de vuelo, con balaustres, lo que se corresponderá con el llamativo dibujo de Palomares, suprimido en la moderna restauración, siendo sustituido por el actual ajimez. En la tribuna del interior del templo se haría una ventana tapiando el resto de la barandilla, llegando así hasta la moderna restauración. Por suerte el imaginado portal no fue llevado a cabo pues hubiera ocultado la hermosa fachada principal.

En la segunda mitad del siglo XVIII se vuelven a llevar a cabo obras importantes. En un informa se asegura que la cabecera de la antigua sinagoga «se halla bastante devorada hasta altura de 12 pies» debido a la humedad. Fue abierta una profunda y larga zanja en el jardín posterior, entonces de propiedad particular, pero que pronto pasaría al priorato precisamente por los continuos reparos que era necesario ejecutar en aquel punto.

Simultáneamente eran acondicionados los «escudos» (estucos) laterales del altar mayor y armadura por el artesano Francisco Silva por 5.500 reales. Y, sin embargo, no quedó en completas condiciones de uso, por lo que «se pensó en dexar dicha iglesia desierta». El prior recordaba la necesidad de cuidar un edificio que había sido antigua sinagoga y, ahora, templo digno de conservación que no era parroquia por lo que no tenía feligreses ni percibía diezmos, y solo servía para oir misa los dependientes y miembros de la orden. Como no se le atendió, el prior ejecuta las obras por su cuenta. Al finalizar el siglo, fray Antonio de Céspedes compraba y donaba el antes mencionado jardín al priorato ${ }^{10}$ (fig. 2).

\section{Desamparo, desamortizaciones y declaración como Monumento Nacional}

El siglo XIX va a ser decisivo para la iglesia del Tránsito. Se ha dicho que fue utilizada por las tropas francesas lo que no es seguro. Ya al terminar la Guerra habría de ser consolidado el artesonado que era de lo más valioso y amenazaba con venirse al suelo.

\footnotetext{
${ }^{9}$ Biblioteca Nacional de España, ms. 8260: F. Pérez BAYER, De Toletano Hebraeorum Templo (1752), con dibujos de F. J. Palomares (1751).

${ }^{10}$ Las noticias para este capítulo están tomadas de AHN, OM, Archivo histórico de Toledo, n. ${ }^{\circ} 45534,47238,47353$ y 48133.
} 


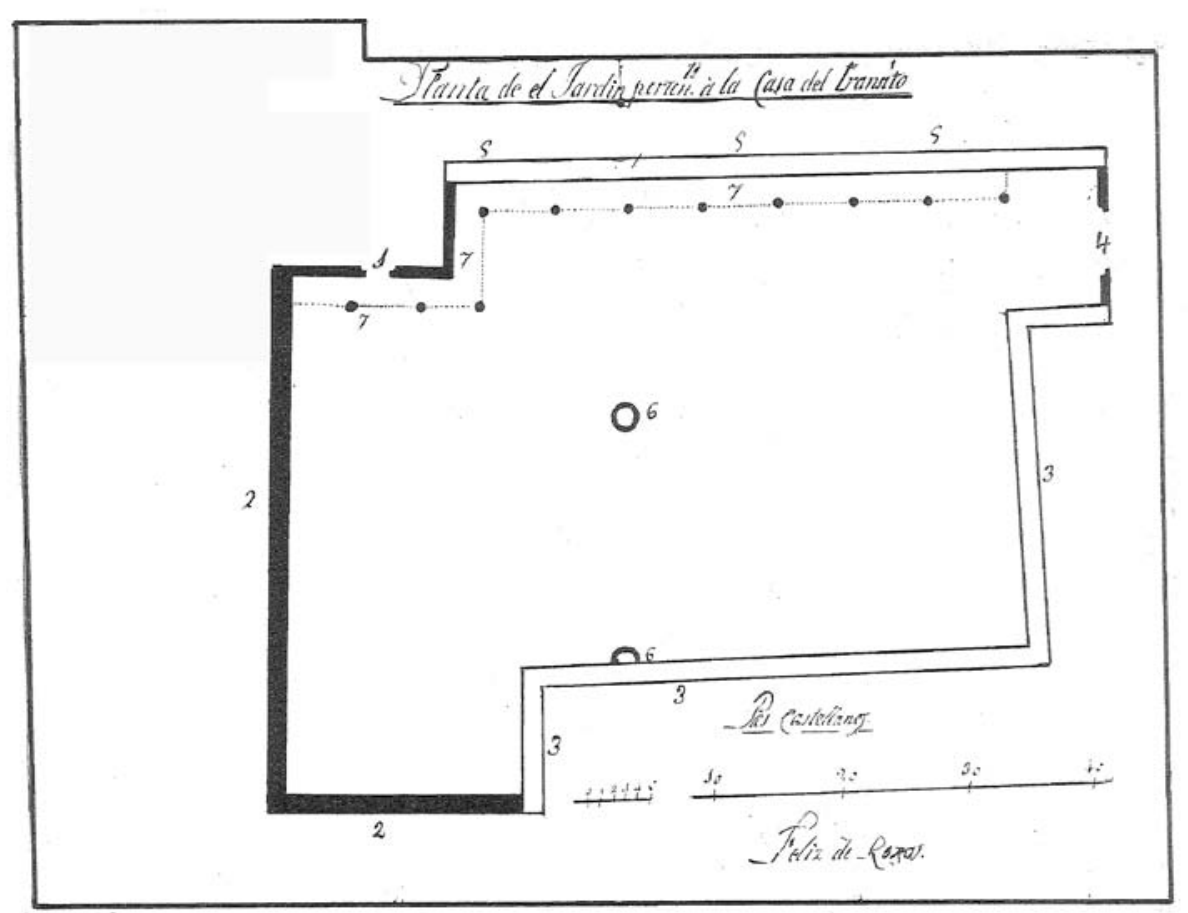

Fig. 2. Jardín de la iglesia del Tránsito, por Félix de Rojas, siglo XVIII ${ }^{11}$. 1. Puerta que comunica la casa con el jardín; 2. Pared de la calle; 3. Pared medianera con casas de San Juan de Dios; 4. Puerta que sale a la plazuela de San Juan de Dios; 5. Pared de la iglesia del Tránsito; 6. Pozos; 7. Descolgadizos.

En 1830 el arquitecto académico de San Fernando, Antonio González de Monroy, reconocía la iglesia. En el inventario-informe que realiza hace constar la donación de numerosos objetos de culto y ornamentación, así como la pérdida de la mayoría de las rentas, sin duda consecuencia de la guerra y enajenaciones del Trienio Liberal. Se ha venido suponiendo incorrectamente que al producirse la Desamortización, esta habría afectado al Tránsito, puesto que habían sido incautados dos cuadros de Correa de Vivar. De hecho, la Real Academia de Bellas Artes de San Fernando y el ministerio nombraron al pintor de cámara Juan

${ }^{11}$ AHN, OM, leg. 4345; croquis dibujado para fijar la donación de una parcela de jardín por el comendador fray Antonio de Céspedes. 
Gálvez, como comisario para recoger las obras de arte más interesantes, y este traslada el valioso cuadro del Tránsito de Correa de Vivar a la Academia, desde donde pasó al Museo de la Trinidad y, de aquí, al Prado ${ }^{12}$.

Mientras tanto, se fue agravando la situación de la vieja sinagoga, olvidada y cerrada al culto desde hacía años, siendo delicada la situación de la cubierta «cuya lluvia menoscaba el precioso artesonado que es de ébano». El año 1873 resultó trascendental para el edificio. Tras la supresión de las órdenes militares, la propiedad del edificio quedó imprecisa. La Comisión de Monumentos expuso que debía ser conservada la iglesia a toda costa como monumento de extraordinario mérito, reclamando su entrega y solicitando su declaración como Monumento Nacional. Años después se insistía que el edificio,

se encuentra en estado de lastimoso abandono, roto y casi destruido el caballete de su techumbre, penetra la lluvia a torrentes a través del magnífico artesonado que cubre su única hermosa nave, amenazando una ruina no lejana [... aunque la petición] se estrella siempre contra la tenaz resistencia de los caballeros de la orden que se oponen a toda cesión en cualquier concepto y que no se cuidan, por otra parte, de defender aquel bello templo de la destrucción de la acción del tiempo. Creado hoy el coto redondo de las órdenes y hallándose la sinagoga de Toledo fuera de su demarcación, parece llegado el caso de que el edificio entre a formar parte de la propiedad nacional y que en cuanto a la jurisdicción eclesiástica quede sujeta al cardenal arzobispo de la diócesis ${ }^{13}$.

Efectivamente, el 1 de mayo de 1877 el Tránsito era declarado Monumento Histórico-Artístico Nacional, entregado a la Comisión que comenzó su restauración. Un tiempo después el arquitecto Francisco Isidori y Ronda limpiaba los desconches de los muros y consolidaba las inscripciones hebreas, aunque tan libremente que su intervención fue criticada y suspendida. Ayudó algo la Diputación Provincial y Real Academia de Bellas Artes. Por otro lado, se pretendía aislar el edificio de su entorno más inmediato, lo que no parecía lo más adecuado, pues este constituía parte de su historia.

La restauración del artesonado debía hacerse «con la colocación de los fondos y rosetones hoy deteriorados, que se reaviven las pinturas, dorados y bellísimos arabescos que antes tenían». Se solicitaba entonces que todo se realizara bajo

\footnotetext{
${ }^{12}$ CAdiÑanos BARdeCI, «Precisiones acerca del Tránsito de la Virgen», págs. 6-13.

${ }^{13}$ Archivo de la Real Academia de Bellas Artes de San Fernando, leg. 53, n. ${ }^{\circ}$ 2/2.
} 
la exclusiva dirección de la Comisión sin intervención alguna de eclesiásticos y que no se destinase al culto una vez restaurada pues la estancia de personas, el humo de las velas e incienso perjudicarían a las pinturas, además de quedar ciertos adornos ocultos por los retablos.

Pronto se reanudaron los trabajos como lo recordaba dicha Comisión: «la atinada y esmerada ejecución [...] la científica restauración de la importante ermita del Tránsito» bajo la dirección del arquitecto Elías Gallego y con el visto bueno de la Academia de San Fernando. La inversión fue de 5.750 reales. ${ }^{14}$.

El agotamiento de los recursos económicos y las dificultades políticas volvieron a paralizar las obras a finales de siglo. A pesar de la suspensión de las obras, el andamiaje instalado por Isidori se mantiene durante los primeros años del siglo XX como lo constatan las fotografías publicadas por Rodrigo Amador de los Ríos ${ }^{15}$.

Recibido: 01/05/2009

Aceptado: 08/07/2010

\footnotetext{
${ }^{14}$ Archivo de la Real Academia de Bellas Artes de San Fernando, legs. 45, n. ${ }^{\circ}$ 4/4 y 53, n. ${ }^{\circ}$ 2/2 (Actas de la Comisión de Monumentos... Expediente de la sinagoga del Tránsito).

${ }^{15}$ R. Amador de los Rios, Monumentos arquitectónicos de España. Toledo (Madrid 1905), págs. 242-269.
} 